\title{
Differential patterns of memory performance in relapsing, remitting and secondary progressive multiple sclerosis
}

\author{
Marina A. Drake, Adriana Carrá, Ricardo F. Allegri, Geraldine Luetic \\ Department of Neurology, Buenos Aires British Hospital, Perdriel 74 Buenos Aires, Argentina
}

Background: Memory dysfunction is common in multiple sclerosis (MS). A retrieval failure has been reported as the primary cause for the memory deficits, although some studies also described a faulty acquisition. Aims: The aim of the study was to examine memory function in relapsing remitting (RR) and secondary progressive (SP) MS patients, analyze the patterns of performance and to investigate whether disease course influences this performance. Design and settings: Case-control prospective study conducted in a clinical setting. Materials and Methods: Fifty-five RR, 23 SP MS patients and 80 normal subjects were evaluated with a comprehensive neuropsychological battery. Memory was assessed with tasks from the Signoret memory battery. Attention and executive function were also assessed. Statistical Analysis: Univariate analysis of variance, Mann-Whitney U-test, multivariate logistic regression and Chi-square test were used as appropriate. Results: MS patients performed significantly worse than controls on almost all measures of memory $(P<0,001)$. MS subgroups differed in tasks of delayed recall (logical memory- $P=0,019$; wordlist delayed recall, $P<0,001$ ), semantic cued recall $(P<0,001)$, recognition trials $(P=0,006)$ rate of forgetting $(P<0,001)$ and confabulation and intrusion errors $(P=0,004)$. Conclusions: Memory is consistently impaired in MS patients and disease course differentially affects the pattern of performance. SP patients show greater difficulties and a more pervasive pattern of dysfunction than RR patients. Delayed recall was the most affected memory measure and performance on this task discriminates between RR and SP MS patients. Relapsing remitting patients performed within the mildly impaired range while SP patients showed a moderate to severe impairment.

Key words: Cognition, memory, multiple sclerosis, neuropsychology
Cognitive impairment can be one of the various manifestations of MS. About $50 \%$ of MS patients present some degree of neuropsychological dysfunction. ${ }^{[1-4]}$ The pattern of cognitive decline is not uniform. Attention, memory, executive-functioning and information processing speed are typically affected by MS. ${ }^{[2]}$ Language and constructional abilities are commonly preserved..$^{[5]}$ Memory impairment has been considered the most common form of cognitive dysfunction. ${ }^{[2,6,7]}$

Memory is not equally affected by the disease. ${ }^{[8]}$ The impairment is often found affecting episodic memory and working memory, while semantic memory, implicit memory and primary short-term memory appear to be intact. ${ }^{[2]}$

A retrieval failure has often been reported as the primary cause of the episodic memory impairment with relative preservation of the encoding and storage mechanisms. ${ }^{[9,10]}$ Multiple sclerosis patients' performances on memory tests typically show difficulties in effortful free recall tasks with normal results in recognition trials. This pattern of performance has been referred as "subcortical".

Other investigators, however, have explained the memory deficits as the result of an inadequate learning ${ }^{[11]}$ or as a deficient encoding. ${ }^{[12-15]}$

At the individual level, the pattern and degree of impairment can vary significantly ${ }^{[16-20]}$ probably due to the heterogeneity of this population in terms of variables such as disease course, disease duration, lesion load, brain region(s) involved and level of functional disability. ${ }^{[21-24]}$

Studies addressing the relationship between these variables and memory impairment have yielded equivocal results. Most investigations have failed to find any association between memory impairment and physical disability or illness duration. ${ }^{[5,6,23,25-27]}$ However, some recent longitudinal data have revealed a slight progression of the cognitive impairment over the years in an important proportion of patients. . $^{[2,17,23,28,29]}$

While most studies suggest that a progressive course is associated with a more severe memory impairment, ${ }^{[30-32]}$ others have failed to replicate this association. ${ }^{[33,34]}$ In most of these previous studies, 
however, there was not a clear distinction between different subtypes of progressive forms and patients were classified under the general label of "chronic-progressive". Due to the increase of reports on the difference in pathology between chronic subtypes, it was recommended ${ }^{[35]}$ that chronic subtypes (i.e., secondary progressive (SPMS) and primary progressive MS (PPMS)) be differentiated. Studies that have addressed the cognitive patterns of the different MS subtypes according to these recommendations ${ }^{[36-39]}$ have reported greater cognitive impairment in SPMS patients compared to PPMS and relapsing remitting (RRMS) patients.

The aim of the present study was to examine memory function in RRMS and SPMS patients and to investigate whether disease course has an effect on this performance.

\section{Materials and Methods}

Seventy-eight patients with clinically definite MS according to Poser ${ }^{[40]}$ criteria were recruited from our department of Neurology during a 24-month period. Fifty-five patients had RRMS (71\%) and 23 had SPMS (29\%). Relapsing remitting MS (RRMS) was defined by the presence of acute attacks with full recovery or with residual deficit upon recovery and clear course of relapses and remissions. Secondary progressive MS (SPMS) was defined by progression (with or without occasional superimposed relapses, minor remissions or plateaus) after an initial RRMS. No exacerbations were present at the moment of the assessment. Median relapse rate was 0,54 .

Eighty normal control subjects (NC) were also evaluated. Patients or NC with a history of psychiatric or neurological illness (other than MS) were excluded. All patients signed an informed consent to participate in this study.

Groups did not differ with regard to demographic variables (age, gender and years of education). Level of disability was measured with the Expanded Disability Status Scale (EDSS). ${ }^{[41]}$ Comparison of the EDSS score between groups revealed significant differences $(P<0,0001)$ [Table 1].

All patients and controls underwent a comprehensive neuropsychological examination. For the present study the following tests were considered:

Episodic memory was assessed with subtests from Signoret's

\begin{tabular}{lcccc}
\hline \multicolumn{4}{c}{ Table 1: } & Demographic and clinical characteristics \\
\hline & $\mathbf{N C}$ & $\mathbf{R R M S}$ & $\mathbf{S P M S}$ & $\boldsymbol{P}$ \\
& $\mathbf{n}=\mathbf{8 0}$ & $\mathbf{n = 5 5}$ & $\mathbf{n}=\mathbf{2 3}$ & \\
Mean (SD) & Mean (SD) & Mean (SD) & \\
Age-years & 44,2 & 42,39 & 46,56 & \\
& $(13,04)$ & $(9,31)$ & $(7,8)$ & $\mathrm{NS}^{*}$ \\
Education-years & 14.25 & 13,82 & 13,52 & \\
& $(6,30)$ & $(3,13)$ & $(3,76)$ & $\mathrm{NS}^{*}$ \\
Gender (m/f) & $28 / 53$ & $18 / 38$ & $9 / 14$ & $\mathrm{NS}^{\dagger}$ \\
Illness duration- & 12,00 & 14,60 & & \\
years & $(8,48)$ & $(6,90)$ & $\mathrm{NS}$ & \\
EDSS score & - & $2.40(1.21)$ & $4,69(1,87)$ & $<0,001^{\ddagger}$ \\
\hline
\end{tabular}

$\mathrm{NC}=$ Normal controls $; \mathrm{RRMS}=$ Relapsing remitting multiple sclerosis; SPMS $=$ Secondary progressive multiple sclerosis; EDSS = Expanded disability status Scale; SD = Standard deviation; NS = Not significant, *ANOVA, ${ }^{+}$Chi-square, ¥Mann-Whitney test memory battery: ${ }^{[42]}$ a) logical memory: (a task of immediate(LMI) and delayed recall of a story (LM-D)); b) word-list learning (auditory verbal learning of a list of 12 words along three trials); c) delayed free recall (free recall of the list after a 10-min delay); d) cued recall (semantic cueing for items not spontaneously remembered); e) recognition (a multiple-choice recognition task). Performance on logical memory subtest was measured by the number of semantic units recalled on each trial and the presence/ absence of confabulation (additions and elaborations not present in the story). The word-list scoring procedure included number of correct responses in each of the three trials (WLT1; WLT2; WLT3); total words recalled across three trials (WLT1 + $2+$ $3)$, difference between words recalled at WLT1 and those recalled at WLT3, as an indication of learning gains (LG); words produced at delayed free recall (DFR); on semantic cued recall (SCR) and on recognition trial (RT). Forgetting index (FI) (differences between performance on learning trials and on DFR), was also computed. Perseveration errors (unintentional iteration of items on a same trial) as well as intrusion errors (production of items not present in the list) were additionally considered.

Testing of attention comprised the Trail Making Test-form A (TMT-A), ${ }^{[43]}$ the Digit Span subtest (forward and backwards) from the Wechsler Adult Intelligence Scale $\mathrm{III}^{[44]}$ and the "7subtraction task" from the Mini Mental State Exam. ${ }^{[45]}$

The Trail Making Test-form B (TMT-B) and the phonological fluency task (total of words beginning with the letter $\mathrm{p}$ generated in one minute) were used as measures of executive functioning. In order to avoid any motor confounds on the TMT, a difference score was obtained by subtracting time to perform Part A from time to perform Part B (TMT B-A). This score is considered a purer indicator of executive function.

Every test score was further converted to Z-score based on the performance of NC subjects. An overall score for each of the three domains was calculated to allow for comparison between functions. The memory score consisted of the average Z-scores obtained on: LM-I, LM-D, WLT3, DFR. The attention score represented the mean Z-score obtained in digit span forward, digit span backward and the 7 -subtraction task. The executive function score consisted of the mean Z-score of performance on TMT B- A and on phonological fluency.

The average of these three functions' Z-scores yielded a general cognitive score.

Performance was considered normal if Z-scores were higher than -1; mildly dysfunctional if Z-scores were between -1 and -2 and moderately to severely impaired if they were lower than -2 .

These function scores allowed for domain comparisons between groups as well as for within group comparison across domains.

\section{Statistical analysis}

Statistical analyses were performed using GraphPad Prism Statistical Software version 4.00. ${ }^{[46]}$ Most differences among groups were evaluated with univariate analysis of variance (ANOVA) followed by Tukey posthoc test. When only two groups were compared, unpaired t-test was used. If data was not normally 
distributed Mann-Whitney test or Kruskal-Wallis test with Dunn post test were used, as appropriate. Additionally, logistic regression was performed to examine differences in memory variables between $\mathrm{NC}$ and MS patients and between RRMS and SPMS and to determine which of these memory processes was more affected in MS patients.

Chi-square was used to evaluate group differences in gender, presence of confabulation, intrusion or perseveration errors in memory tests and level of cognitive impairment. To explore the possible relationship between performance on certain cognitive tasks and other variables (i.e., EDSS score, illness duration) Spearman's rank correlation coefficient was used.

\section{Results}

Comparison between total MS patients and NC subjects [Table 2 ] showed highly significant differences $(P<0,001)$ in almost all memory measures examined, with the exception of $\mathrm{LG}$, in which both groups performed similarly $(P=0,284)$. Multivariate analysis revealed that LM-D (odds ratio $(\mathrm{OR}): 1,784 ; 95 \%$ confidence interval (CI): $1.397-2,278 ; P=0.0001$ ) and DFR (OR: 1,780 CI: $1,342-2.359 ; P=0.0001$ ) were the best predictors of group membership (MS or NC).

When MS patients were subdivided according to clinical course [Table 3; Figure 1], it was found that on LM-I and LM-D both MS groups differed from the $\mathrm{NC}$ group $(P<0,001)$, but no significant differences were seen between patients groups. Significant differences between SPMS and RRMS patients were found on forgetting index of the story and on confabulation errors. The SPMS group showed greater loss of the story previously recalled $(P=0.009)$ and a higher rate of confabulation errors $(P=0.004)$.

Analysis of performance on the word-list learning trials indicated that both MS groups differed from the NC $(P<0,001)$ in WLT1; WLT2; WLT3; and WLT1 $+2+3$. Differences between MS groups were seen on WLT1 $(P=0.036)$ and total of words learned across WLT1 $+2+3(P=0.019)$, in both cases the SPMS group recalled significantly fewer words than the RRMS patients.

No significant differences were found $(P=0.943)$ on LG.
On DFR and SCR both MS groups differed from the NC $(P<0,001)$, with the SPMS group performing significantly worse than the RRMS group on both measures $(P<0,001)$. On RT no differences were found between RRMS patients and the NC group $(P=0,093)$, but the SPMS group differed from RRMS $(P=0,005)$ and $\mathrm{NC}(P<0,001)$.

Rate of forgetting was also significantly different between groups $(P<0,001)$. The SPMS group showed larger losses of words previously learned.

When intrusion errors were considered, no significant differences were seen between RRMS and SPMS although these two groups had significantly more intrusion errors than the NC.

Stepwise logistic regression showed that DFR (OR:,635; 95\% CI: $479-, 842 ; P=0,002)$ was the best predictive memory measure, which discriminated between the SPMS and RRMS groups.

Memory scores of MS patients were transformed into standard Z-scores [Figure 2] on the basis of performance of the NC group. On story recall RRMS patients had a mean Z-score of $-1,55$ on LM-I and of $-1,66$ on LM-D, which corresponds to a mild dysfunction. The SPMS group obtained a mean Z-score of -2,34

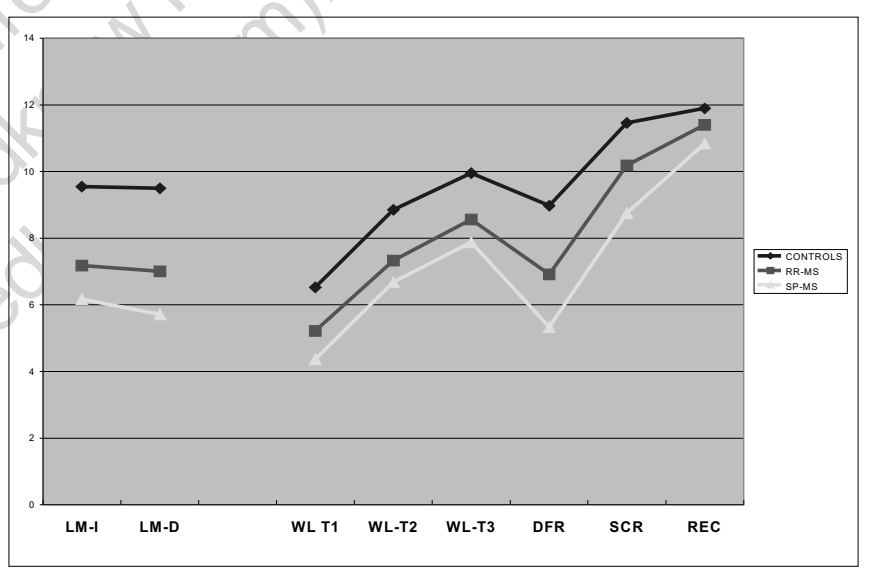

Figure 1: Memory performance of MS subtypes and controls NC = normal controls; RRMS = relapsing remitting multiple sclerosis; SPMS= secondary progressive multiple sclerosis

SR-I :Story recall- immediate trial; SR-D: Story recall-delayed trial;

WL-Tr.1/2/3: Wordlist learning, trial 1/2/3. DFR: Delayed free recall; SCR: Semantic cued recall; REC: Recognition trial

Table 2: Results of memory testing - multiple sclerosis patients vs. normal controls

\begin{tabular}{|c|c|c|c|c|c|}
\hline \multirow[t]{2}{*}{ Long-term episodic memory } & \multirow{2}{*}{$\begin{array}{c}\text { Multiples clerosis } \\
(\mathrm{n}=78) \\
\text { Mean (SD) }\end{array}$} & \multirow{2}{*}{$\begin{array}{c}\text { Normal controls } \\
(n=80) \\
\text { Mean (SD) }\end{array}$} & \multirow[t]{2}{*}{$F(3,90)$} & \multicolumn{2}{|c|}{$95 \% \mathrm{Cl}$} \\
\hline & & & & & \\
\hline Story recall (immediate) & $6.81(2.57)$ & $9.54(1.5)$ & $64,55^{*}$ & 3,45 & $-2,09$ \\
\hline Wordlist learning - trial 1 & $4.87(1.16)$ & $6,52(1.56)$ & $36,98^{*}$ & $-2,18$ & $-1,11$ \\
\hline Wordlist learning - trial 2 & $6.9(1.8)$ & $8.85(1.2)$ & $31,87^{*}$ & $-2,34$ & $-1,12$ \\
\hline Wordlist learning - trial 3 & $8.32(1,87)$ & $9.95(1.35)$ & $38,70^{*}$ & $-2,08$ & $-1,08$ \\
\hline Wordlist learning - total $(\mathrm{T} 1+\mathrm{T} 2+\mathrm{T} 3)$ & $20,26(4,48)$ & $25.47(3.14)$ & $46,90^{*}$ & $-6,59$ & $-3,67$ \\
\hline Delayed free recall & $6.49(2.05)$ & $8.98(1.56)$ & $59,86^{*}$ & $-3,01$ & $-1,79$ \\
\hline Recall with semantic cue & $9.89(1.72)$ & $11.46(0.86)$ & $36,36^{*}$ & $-2,04$ & $-1,04$ \\
\hline Recognition & $11.30(0,85)$ & $11.89(0.41)$ & $17,78^{*}$ & $-0,85$ & $-0,31$ \\
\hline Forgetting index & $0.23(0,15)$ & $0.11(0.1)$ & $22,73^{*}$ & 0,08 & 0,18 \\
\hline
\end{tabular}

$\mathrm{Cl}=$ Confidence interval, ${ }^{*} P<0,001,{ }^{+}$Not significant 
Table 3: Results of cognitive testing by disease course

\begin{tabular}{|c|c|c|c|c|c|c|c|}
\hline \multirow{2}{*}{ Long-term episodic memory } & \multirow{2}{*}{$\begin{array}{c}\text { NC } \\
\text { Mean (SD) } \\
9.54(1.5)\end{array}$} & \multirow{2}{*}{$\begin{array}{c}\text { RRMS } \\
\text { Mean (SD) } \\
7,16(2.57)\end{array}$} & \multirow{2}{*}{$\begin{array}{c}\text { SPMS } \\
\text { Mean (SD) } \\
5,96(2.55)\end{array}$} & \multirow{2}{*}{$\begin{array}{c}\mathbf{F}(\mathbf{3}, \mathbf{0 6}) \\
35,93\end{array}$} & \multicolumn{2}{|c|}{$95 \% \mathrm{Cl}$} & \multirow{2}{*}{$\begin{array}{c}P^{\S} \\
P<0,001^{* *}\end{array}$} \\
\hline & & & & & & & \\
\hline Story recall (immediate) & & & & & $\begin{array}{l}1.46 \\
2.43 \\
0.02\end{array}$ & $\begin{array}{l}3.26^{*} \\
4.75^{\dagger}\end{array}$ & \\
\hline \multirow{3}{*}{ Story recall (delayed) } & $9.50(1.48)$ & $6,99(2.55)$ & $5,32(2,98)$ & 41,49 & $\begin{array}{c}-0.02 \\
1.51\end{array}$ & $\begin{array}{l}2.47^{\ddagger} \\
3.36^{*}\end{array}$ & $P<0,001^{* *}$ \\
\hline & & & & & 2.97 & $5.40^{\dagger}$ & \\
\hline & & & & & 0.44 & $3.05^{\ddagger}$ & \\
\hline \multirow[t]{3}{*}{ Story recall-forgetting Index } & $0,01(0,06)$ & $0,08(0.79)$ & $0,17(0,28)$ & 4,57 & -0.09 & $0.11^{*}$ & $P<0,001^{\dagger \dagger}$ \\
\hline & & & & & -0.30 & $-0.047^{\dagger}$ & \\
\hline & & & & & -0.32 & $-0.047^{\ddagger}$ & \\
\hline \multirow[t]{3}{*}{ Wordlist learning - trial 1} & $6,52(1.56)$ & $5,13(1,16)$ & $4,26(1,60)$ & 22,45 & 0.68 & 2.04 & $P<0,001^{\ddagger \ddagger}$ \\
\hline & & & & & $* 1.49$ & $3.12^{\dagger}$ & \\
\hline & & & & & 0.05 & $1.75^{\ddagger}$ & \\
\hline \multirow[t]{2}{*}{ Wordlist learning - trial 3} & $9.95(1.35)$ & $8.58(1.87)$ & $7.73(1.71)$ & & 0.63 & $1.95^{\star}$ & $P<0,001^{* *}$ \\
\hline & & & & & $-0 . .01$ & $1.85^{\ddagger}$ & \\
\hline \multirow[t]{2}{*}{ Wordlist learning - total $(\mathrm{T} 1+\mathrm{T} 2+\mathrm{T} 3)$} & $25.47(3.14)$ & $21.02(4.34)$ & 18,52 & & 2.E's & $6.35^{*}$ & $P<0,001^{\ddagger \ddagger}$ \\
\hline & & & & & & $4.84^{\ddagger}$ & \\
\hline \multirow[t]{2}{*}{ Learning gains (T3-T1) } & $3,60(1,68)$ & $3,61(1,37)$ & $3,73(1,3$ & c & -0.72 & $0.71^{*}$ & NS \\
\hline & & & & & $\begin{array}{l}-1.04 \\
2.55\end{array}$ & $\begin{array}{l}0.79^{\dagger} \\
6.35^{\ddagger}\end{array}$ & \\
\hline \multirow[t]{3}{*}{ Delayed free recall } & $8.98(1.56)$ & 7.02 (2.04) & & 41,64 & 1.02 & $2.58^{\star}$ & $P<0,001^{\text {执 }}$ \\
\hline & & & & & 2.69 & $4.74^{\dagger}$ & \\
\hline & & & & & 0.82 & $3.02^{\ddagger}$ & \\
\hline \multirow[t]{2}{*}{ Cued recall } & $11.46(0.86)$ & 10 & & 27,06 & 0.43 & $1.72^{*}$ & $P<0,001^{\text {㧊 }}$ \\
\hline & & & & & $\begin{array}{l}1.69 \\
0.56\end{array}$ & $2.38^{\ddagger}$ & \\
\hline \multirow[t]{2}{*}{ Recognition } & $11.89(0.41)$ & & $(1,66)$ & 14,24 & 0.02 & $0.72^{*}$ & $P<0,001^{\text {t十 }}$ \\
\hline & & & & & 0.56 & $1.48^{\dagger}$ & \\
\hline \multirow{3}{*}{ Forgetting index } & $0,11(0.12)$ & $0 . i c(0,15)$ & $0.34(0.28)$ & 20.63 & 0.16 & $1.14^{\ddagger}$ & 殒 \\
\hline & & & & & $\begin{array}{l}-0.16 \\
-0.33\end{array}$ & $\begin{array}{l}-0.0< \\
-0.15^{\dagger}\end{array}$ & $r<0,001$ \\
\hline & & & & & -0.25 & $-0.05^{\ddagger}$ & \\
\hline
\end{tabular}

$\mathrm{NC}=$ Normal controls, RRMS $=$ Relapsing remitting multiplt s : lerosis, SPMS $=$ Secondary progressive multiple sclerosis, SD $=$ Standard deviation, $\mathrm{Cl}=$ Confidence interval, NS $=$ Not significant, ${ }^{*}=\mathrm{NC}$ vs. $\mathrm{Pr},{ }^{\dagger}=\mathrm{NC}$ vs. SP, ${ }^{\ddagger}=\mathrm{RR}$ vs. SP, ${ }^{\S}=$ ANOVA, ${ }^{* *}=$ RRMS and SPMS differ significantly from NC,

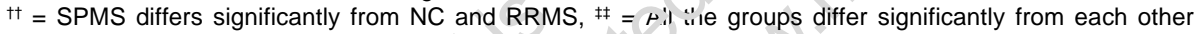

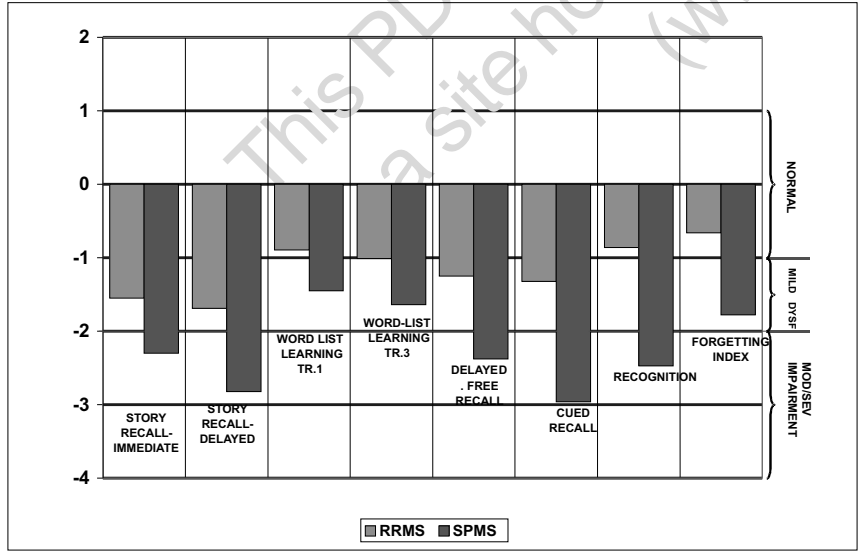

Figure 2: Memory performance of MS subtypes. Severity of impairment, RRMS = Relapsing remitting multiple sclerosis, SPMS = Secondary progressive multiple sclerosis, Mild dysf = Mild dysfunction, Mod/sev impairment = Moderate to severe impairment

on LM-I and -2,89 on LM-D, evidencing a moderate/severe impairment. On WLT1 and WLT3, RRMS patients had a mean score of $-0,88$ and $-1,01$, showing normal functioning and very mild dysfunction respectively. Mean Z-scores for WLT1 and WLT3 for the SPMS were $-1,45$ and 1,64 respectively, both indicative of mild impairment. Relapsing remitting MS patients obtained the following mean Z-scores: $-1,24$ on DFR, -1,32 on SCR and $-0,88$ on RT. Performance of the SPMS group on these tasks showed a mean Z-score of -2, 37 for the DFR, $-2,57$ for the SCR and $-2,79$ for the RT, all evidencing a moderate/severe impairment.

\section{Additional cognitive assessment: [Table 4]}

General Cognitive Status: Performance on the MMSE was significantly different among groups $(P<0,001)$. Mean performance score of the SPMS group differed from that of the RRMS $(P=0,02)$ and the NC $(P<0,001)$ groups. The RRMS did not differ from $\mathrm{NC}(P=0,119)$.

Attentional skills: Highly significant differences were seen in all measures of attention $(P<0,001)$. Posthoc tests revealed a significant worse performance of both MS groups than that of NC subjects $(P<0,001)$. The RRMS and the SPMS, however, performed at a similar level $(P>0,05)$ in all tests.

Executive functioning: Groups differed with regard to performance on the TMT BA $(P<0,001)$. Both groups of MS differed significantly from the $\mathrm{NC}$ group $(P<0,001)$ but they performed similar to one another $(P=0,067)$. On the phonological 
Table 4: Results of additional neuropsychological measures

\begin{tabular}{|c|c|c|c|c|c|c|c|}
\hline General cognitive status & \multirow{2}{*}{$\begin{array}{c}\text { NC } \\
\text { Mean (SD) } \\
29.22(0.7)\end{array}$} & \multirow{2}{*}{$\begin{array}{c}\text { RRMS } \\
\text { Mean (SD) } \\
28.70(1,57)\end{array}$} & \multirow{2}{*}{$\begin{array}{c}\text { SPMS } \\
\text { Mean (SD) } \\
27.91(1.12)\end{array}$} & \multirow{2}{*}{$\begin{array}{c}\mathbf{F} \\
(3,06) \\
22,70\end{array}$} & \multicolumn{2}{|c|}{$95 \% \mathrm{Cl}$} & \multirow{2}{*}{$\begin{array}{c}\boldsymbol{P} \\
P<0,001^{\S}\end{array}$} \\
\hline Mini mental state exam & & & & & $\begin{array}{l}-0.07 \\
0.71 \\
0.30\end{array}$ & $\begin{array}{l}0.82 \\
1.90 \\
1.56\end{array}$ & \\
\hline \multicolumn{8}{|l|}{ Attention } \\
\hline Digit span forward & $6.73(0,87)$ & $5.56(1.18)$ & $5.60(0,89)$ & 27,77 & $\begin{array}{c}0.73 \\
0.58 \\
-0.61\end{array}$ & $\begin{array}{l}1.56 \\
1.68 \\
0.57\end{array}$ & $P<0,001^{* *}$ \\
\hline Digit span backward & $4.85(0,98)$ & $4.16(1,26)$ & $3.63(0,95)$ & 10,74 & $\begin{array}{c}0.15 \\
0.53 \\
-0.15\end{array}$ & $\begin{array}{l}1.17 \\
1.90 \\
1.27\end{array}$ & $P<0,001^{* *}$ \\
\hline Serial subtraction (7) & $4,48(1,06)$ & $3,19,(1,69)$ & $3,39(1,30)$ & 14,13 & $\begin{array}{c}0.66 \\
0.30 \\
-1.00\end{array}$ & $\begin{array}{l}1.88 \\
1.87 \\
0.63\end{array}$ & $P<0,001^{* *}$ \\
\hline \multicolumn{8}{|l|}{ Executive function } \\
\hline Phonological word fluency & $18,05(4,18)$ & $13,24(4,48)$ & $12,00(4,30)$ & & $\begin{array}{r}2.73 \\
3.57 \\
-1.18\end{array}$ & $\begin{array}{l}6.48 \\
8.53 \\
4.08\end{array}$ & $P<0,001^{* *}$ \\
\hline Trail making Test - B & $71,06(21,07)$ & $147,6(85,22)$ & $253,90(139,20)$ & & $\begin{array}{l}-111.69 \\
-236.41 \\
-161.11\end{array}$ & $\begin{array}{l}-40.11 \\
-129.33 \\
-52.83\end{array}$ & $P<0,001^{* *}$ \\
\hline Trail making Test - B-A & $33,65(18,14)$ & $85,92(80,52)$ & $145,6(101,80)$ & & $\begin{array}{r}-83.88 \\
-153.62 \\
-101.01\end{array}$ & $\begin{array}{c}-22.39 \\
-61.64 \\
-7.99\end{array}$ & $P<0,001^{* *}$ \\
\hline
\end{tabular}

$\mathrm{NC}=$ Normal controls, RRMS $=$ Relapsing remitting multiple sclerosis, SPMS $=$ Secondary progressive multiple sclerosis, SD $=$ Standard deviation, $\mathrm{Cl}=$ Confidence interval, ${ }^{*}=\mathrm{NC}$ vs. RR, ${ }^{\dagger}=\mathrm{NC}$ vs. SP, ${ }^{\ddagger}=\mathrm{RR}$ vs. SP, ${ }^{\S}=$ SPMS differs significantly from NC and RRMS, ${ }^{\star *}=$ RRMS and SPMS differ from NC

fluency task the same pattern was apparent.

Conversion of raw scores into Z-scores allowed for obtaining a Function Score for every domain studied [Table 5]. Groups did not differ with regard to their Attention Score $(P=0,737)$ or the Executive Function Score $(P=0,104)$. However, in regard to the memory domain, the SPMS group had a mean Memory Score of $-2,26$ which was significantly different $(P=0.004)$ from the mean score of $-1,34$ obtained by the RRMS group.

Comparison of group differences for the General Cognitive Score revealed a significant difference between groups $(P=0,009)$ with the SPMS group obtaining a lower score $(-1,83)$ than that of the RRMS group $(-1,25)$.

The profile of cognitive performance of each group was further analyzed. The intragroup function scores of the three domains were compared in order to see if there were discrepancies in the level of impairment. It was found that the RRMS group performed at a relatively similar level on the three measures; that is, no significant differences were seen relative to performance on attention, memory or executive function $(P=0,073)$. The SPMS group, on the other hand, showed significant differences, performing in a less uniform manner across these domains. Posthoc analyses showed statistically significant differences between attention and memory $(P=0,001)$ and attention and executive function $(P=0,002)$. Level of performance between memory and executive function was relatively similar.

Spearman rank correlation was performed to examine any possible influence of clinical variables such as illness duration and physical disability. When all MS patients were considered (irrespective of subtype) no correlation was found between years from onset of MS and any of the cognitive domains explored (memory, attention and executive function and global cognitive performance). The EDSS score correlated with memory $(r=-$ $0,351, P=0,004)$, executive functioning $(\mathrm{r}=-0,298 ; P<0,024)$ and cognitive performance $(r=-0,358 ; P=0,003)$ but not with attention. $(r=-0,183 ; P=0,132)$. However, when patients were subdivided according to subtypes, no correlation was found between EDSS score and any of the domains explored, neither in the RRMS nor in the SPMS groups.

\section{Discussion}

Our findings confirm the deleterious effect that MS exerts on

\begin{tabular}{|c|c|c|c|c|c|}
\hline \multirow[b]{3}{*}{ Attension score } & \multirow{2}{*}{$\begin{array}{c}\text { RRMS } \\
\text { Mean (SD) }\end{array}$} & \multirow{2}{*}{$\begin{array}{c}\text { SPMS } \\
\text { Mean (SD) }\end{array}$} & \multicolumn{2}{|c|}{$95 \% \mathrm{Cl}$} & \multirow{2}{*}{$P$} \\
\hline & & & & & \\
\hline & $-1,02(1,02)$ & $-1,10(0,82)$ & -0.56 & 0.39 & NS \\
\hline Memory score & $-1,34(1,18)$ & $-2,26(1,34)$ & -1.54 & -0.29 & $P=0.004$ \\
\hline Executive function score & $-1,54(1,51)$ & $-2,31(1,41)$ & -1.67 & 0.13 & NS \\
\hline Global cognitive score & $-1,25(1,03)$ & $-1,83(0,93)$ & -1.08 & -0.08 & $P=0.009$ \\
\hline
\end{tabular}

RRMS = Relapsing remitting multiple sclerosis; SPMS = Secondary progressive multiple sclerosis; SD = Standard deviation; $\mathrm{Cl}=\mathrm{Confidence}$ interval; $\mathrm{NS}=\mathrm{Not}$ significant, MS - Multiple sclerosis 
memory functioning. In this study, when MS patients-regardless of their course-were compared to normal controls, significant differences were found in almost all memory measures examined. Along with the retrieval difficulties that have been considered a "hallmark" of memory impairment in MS, we also found that the acquisition and encoding mechanisms were impaired as well.

Deficits in initial verbal acquisition have been explained by some authors $^{[47]}$ as the effect of a stimulus overload or slowness to deal with new tasks. In agreement with these hypotheses, DeLuca et $a l^{[11]}$ found a correlation between inadequate initial acquisition and processing speed in a group of MS patients.

In our study a faulty encoding mechanism was evident on SCR. In this task, in which the subject is prompted with the item category as a cue to facilitate its recall (i.e., the category "fruit" to elicit the correct response "banana"), MS patients showed significantly lower gains, thus possibly showing difficulty in the semantic organization and encoding of the information stored. Previous studies ${ }^{[15,21,48,49]}$ observed that MS patients may present limitations in the semantic richness of encoding and in flexibly using semantic properties to facilitate recall a. In terms of Craik's levels of processing model, ${ }^{[39,40]}$ which differentiates between a shallow vs. a deep encoding, it seems that MS patients have difficulty in employing a deeper (semantic) method for processing and encoding information.

Although MS patients recalled fewer words along the three learning trials, the progressive increase of words with the successive trials was similar to that of the NC group. This may indicate that MS patients are able to learn and store new information and that they have a relatively intact capacity of improving learning through repetition but that they need a more prolonged exposure to the information to be learned probably due to a defective processing speed..$^{[2,8]}$

In consonance with the retrieval failure hypothesis, on the delayed recall trial MS patients recalled fewer words than $\mathrm{NC}$ and they also showed an abnormal rate of forgetting of the words previously learned. The fact that LM-D and DFR were the best predictive memory measures discriminating between MS and NC subjects seems to support the centrality of the retrieval deficit in this population.

A study of Beatty ${ }^{[50]}$ reported dissociation between performance on a word-list learning task and on story recall with MS patients performing better on story recall than on list recall. Our study does not support such a finding and shows that MS patients are impaired on both tasks. Furthermore, they showed an unusual rate of confabulation errors when recalling the story. These errors, as well as the intrusion errors on the word-list are considered to involve frontal lobe dysfunction.

Multiple sclerosis subgroups differed not only on the magnitude of the impairment but on the components of the memory process as well. The SPMS group showed greater and more pervasive difficulties, performing at significantly lower levels on acquisition of information, confabulation errors and on retrieval tasks, particularly on delayed recall. These findings are consistent with previous studies. ${ }^{[36,37,39]}$
While the SPMS exhibited impairment on all memory measures with the exception of LG, the RRMS group performed at normal levels on retention of the previously learned story, learning gains of wordlist and on recognition memory. That is, the SPMS group had a more widespread memory deficit, while the RRMS showed a more restricted pattern of impairment, resembling the "subcortical pattern" described in the literature.

Performance of RRMS patients on all memory measures fell within the mildly impaired range, while in the case of SPMS patients most memory processes were moderately to severely impaired.

When memory was compared to other cognitive functions we found differences between both groups. The mildly impaired performance on memory measures of RRMS patients was relatively similar to the performance on attention and executive functions, which were also mildly dysfunctional. The pattern of SPMS patients was somewhat different, showing equally severe impairment of memory and executive function but a mild dysfunction of attention. In consonance with our findings, Kraus et $a l^{[39]}$ found that the pattern of major involvement of verbal memory and executive function distinguished SPMS from RRMS.

Disease duration was not related to memory impairment, but disability level, as measured by EDSS, did show a significantalthough modest-correlation with memory and cognitive dysfunction. This correlation, however, disappeared when MS patients were divided into subtype groups, which may be indicative of the confounding effect of disease course in that correlation, as almost by definition SPMS have higher EDSS scores. Some recent studies $^{[5,17,28,37]}$ have revealed that there might be a relationship between cognitive status and disability level, particularly when EDSS scores are high.

\section{Conclusion}

Our findings suggest that disease course can differentially affect memory functioning in MS: SPMS patients show greater difficulties and a more pervasive pattern of dysfunction than RRMS patients. This differential memory dysfunction may be due to the different neurobiological processes that predominate in RRMS and SPMS (inflammation and neural degeneration, respectively). Future studies should aim to investigate the role that pathogenesis plays in the cognitive impairment in MS.

\section{References}

1. Rao SM, Reingold SC, Ron MA, Lyon-Caen O, Comi G. Workshop on Neurobehavioral Disorders in Multiple Sclerosis. Diagnosis, underlying disease, natural history and therapeutic intervention, Bergamo, Italy, June 25-27, 1992. Arch Neurol 1993;50:658-62.

2. Rao SM. Cognitive function in patients with multiple sclerosis: Impairment and treatment. Int J MS Care 2004;1:9-222.

3. Bobholz JA, Rao SM. Cognitive dysfunction in multiple sclerosis: A review of recent developments. Curr Opin Neurol 2003;16:283-8.

4. Heaton RK, Nelson LM, Thompson DS, Burks JS, Franklin GM. Neuropsychological findings in relapsing-remitting and chronic-progressive multiple sclerosis. J Consult Clin Psychol 1985;53:103-10.

5. Amato MP, Zipoli V. Clinical management of cognitive impairment in multiple sclerosis: A review of current evidence. Int MS J 2003;10:72-83. 
6. Thornton AE, Raz N. Memory impairment in multiple sclerosis: A quantitative review. Neuropsychology 1997;11:357-66.

7. Grafman J, Rao SM, Litvan I. Disorders of Memory. In: Rao SM, editor Neurobehavioral Aspects of Multiple Sclerosis, Oxford University Press: New York; 1990. p. 102-17.

8. Brassington JC, Marsh NV. Neuropsychological aspects of multiple sclerosis. Neuropsychol Rev 1998;8:43-77.

9. Coolidge FL, Middleton PA, Griego JA, Schmidt MM. The effects of interference on verbal learning in multiple sclerosis. Arch Clin Neuropsychol 1996;11:605-11.

10. Armstrong C, Onishi K, Robinson K, Desposito M, Thompson H, Rostami A, et al. Serial position and temporal cue effects in multiple sclerosis: Two subtypes of defective memory mechanisms. Neuropsychologia 1996;34:853-62.

11. DeLuca J, Barbieri-Berger S, Johnson SK. The nature of memory impairments in multiple sclerosis: Acquisition versus retrieval. J Clin Exp Neuropsychol 1994;16:183-9

12. DeLuca J, Gaudino EA, Diamond B.J, Christodoulou C, Engel RA. Acquisition and storage deficits in multiple sclerosis Acquisition and storage deficits in multiple. $\mathrm{J}$ Clin Exp Neuropsychol 1998;20:376-90.

13. Ryan L, Clark CM, Klonoff H, Li D, Paty D. Patterns of cognitive impairment in relapsing-remitting multiple sclerosis and their relationship to neuropathology on magnetic resonance images. Neuropsychology 1996;15:563-77.

14. Beatty WW, Wilbanks SL, Blanco CR, Hames KA, Tivis R, Paul RH. Memory disturbance in multiple sclerosis: Reconsideration of patterns of performance on the selective reminding test. J Clin Exp Neuropsychol 1996;18:56-62.

15. Thornton AE, Raz N, Tucke KA. Memory in multiple sclerosis: Contextual encoding deficits. .J Int Neuropsychol Soc 2002;8:395-409.

16. Nocentini U, Pasqualetti P, Bonavita S, Buccafusca M, De Caro MF, Farina D, et al. Cognitive dysfunction in patients with relapsing-remitting multiple sclerosis. Mult Scler 2006;12:77-87.

17. Amato MP, Ponziani G, Siracusa G, Sorbi S. Cognitive dysfunction in early-onset multiple sclerosis: A reappraisal after 10 years. Arch Neurol 2001;58:1602-6.

18. Beatty WW. A strategy for studying memory disorders in multiple sclerosis. In Squire RL, Butters N, editors. Neuropsychology of Memory. Guilford Press: New York, NY; 1992. p. 285-9.

19. Ryan L, Clark CM, Klonoff H, Paty D. Models of cognitive deficit and statistical hypotheses: Multiple sclerosis, an example. J Clin Exp Neuropsychol $1993 ; 15: 563-77$.

20. Zakzanis KK. Distinct neurocognitive profiles in multiple sclerosis subtypes. Arch Clin Neuropsychol 2000;15:115-36.

21. Griffiths SY, Yamamoto A, Boudreau VG, Ross LK, Kozora E, Thornton AE. Memory interference in multiple sclerosis. J Int Neuropsychol Soc 2005;11:737-46.

22. Lazeron RH, Boringa JB, Schouten M, Uitdehaag BM, Berger's E, Lindeboom J, et $a l$. Brain atrophy and lesion load as explaining parameters for cognitive impairment in multiple sclerosis. Mult Scler 2005;11:524-31.

23. Calabrese P. Neuropsychology of multiple sclerosis-An overview. J Neurol 2006;253:10-5.

24. Deloire MS, Salort E, Bonnet M, Arimone Y, Boudineau M, Amieva H, et al. Cognitive impairment as marker of diffuse brain abnormalities in early relapsing remitting multiple sclerosis. J Neurol Neurosurg Psychiatry 2005;76:519-26.

25. Rao SM, Grafman J, DiGiulio D, Mittemberg W, Bernardin L, Leo G, et al. Memory dysfunction in multiple selerosis: Its relation to working memory, semantic encoding and implicit learning. Neuropsychology 1993;7:364-74.

26. Jennekens-Schinkel A, Lanser JB, van der Velde EA. Neuropsychological assessment in patients with multiple selerosis and mild functional impairment. $J$ Neurol Neurosurg Psychiatry 1991;54:757.

27. Maureli M, Marchioni E, Cerretano R, Bosone D, Bergamaschi R, Citterio A, et al. Neuropsychological assessment in MS: clinical, neuropsychological and neuroradiological relationships. Acta Neurol Scand 1992;86:124-8.

28. Amato MP, Zipoli V, Portaccio E. Multiple sclerosis-related cognitive changes: A review of cross-sectional and longitudinal studies. J Neurol Sci 2006;245:41-6.

29. Bagert B, Camplair P, Bourdette D. Cognitive dysfunction in multiple sclerosis
Natural history, pathophysiology and management. CNS Drugs 2002;16:445-55.

30. Filley C, Heaton RK, Thompson L, Nelson L, Franklin G. Effects of disease course on neuropsychological functioning. In: Rao SM, editor. Neurobehavioral Aspects of Multiple Sclerosis. Oxford University Press: New York; 1990. p. 136-48.

31. Feinstein A, Kartsounis LD, Miller DH, Youl BD, Ron MA. Clinically isolated lesion of the type seen in multiple sclerosis: A cognitive, psychiatric and MRI follow up study. .J Neurol Neurosurg Psychiatry 1992;55:869-76.

32. Beatty WW, Goodkin DE, Monson N, Beatty PA, Hertsgaard D. Anterograde and retrograde amnesia in patients with chronic progressive multiple sclerosis. Arch Neurol 1988;45:611-9.

33. Rao SM, Leo G.J, Bernardin L, Unverzagt F. Cognitive dysfunction in multiple sclerosis. I. Frequency, patterns and prediction. Neurology 1990;41:685-91.

34. Beatty WW, Goodkin DE, Hertsgaard D, Monson N. Clinical and demographic predictors of cognitive performance in multiple sclerosis. Do diagnostic type, disease duration and disability matter? Arch Neurol 1990;47:305-8.

35. Lublin FD, Reingold SC. Defining the clinical course of multiple sclerosis: Results of an international survey. Neurology 1996;46:907-11.

36. Gaudino EA, Chiaravalloti ND, DeLuca J, Diamond BJ. A comparison of memory performance in relapsing-remitting, primary progressive and secondary progressive, multiple sclerosis. Neuropsychiatry Neuropsychol Behav Neurol 2001;14:32-44.

37. Huijbregts CJ, Kalkers NF, de Sonneville LM, de Groot V, Reuling IE, Polman CH Differences in cognitive impairment of relapsing remitting, secondary and primary progressive MS. Neurology 2004;63:335-9.

38. De Sonneville LM, Boringa JB, Reuling IE, Lazeron RH, Ader HJ, Polman CH Information processing characteristics in subtypes of multiple sclerosis. Neuropsychologia 2002;40:1751-65.

39. Kraus JA, Schutze C, Brokate B, Kroger B, Schwendemann G, Hildebrandt H. Discriminant analysis of the cognitive performance profile of MS patients differentiates their clinical course. J Neurol 2005;252:808-13.

40. Poser CM, Paty DW, Scheinberg L, McDonald I, Davis FA, Ebers GC, et al. New diagnostic criteria for multiple sclerosis: Guidelines for research protocols. Ann Neurol 1983;13:227-31.

41. Kurtzke JF. Rating neurologic impairment in multiple sclerosis: An expanded disability status seale (EDSS). Neurology 1983;33:1444-52.

42. Sign Signoret JL, Whiteley A. A memory battery scale. Int Neuropsychol Soc Bull 1979;226.

Reitan RM. Validity of the trail making test as an indicator of organic brain damage. Percept Mot Skills 1958;8:271-6.

44. Wechsler D. Wechsler Adult Intelligence Scale- $3^{\text {rd }}$ ed. The Psychological Corporation: San Antonio, TX; 1997.

Folstein MF, Folstein SE, McHugh PR. "Mini-Mental State": A practical method for grading the cognitive state of patients for the clinician. J Psychiatr Res $1975 ; 12: 189-98$

46. GraphPad Prism version 4.00 for Windows, GraphPad Software: San Diego California USA.

47. Lezak, MD. Neuropsychological Assessment. Oxford University Press: New York; 1995

48. Carroll M, Gates R, Roldan F. Memory impairment in multiple sclerosis. Neuropsychologia 1984;22:297-302.

49. Beatty WW, Goodkin DE, Beatty PA, Monson N. Frontal lobe dysfunction and memory impairment in patients with chronic progressive multiple sclerosis. Brain Cogn 1989;11:73-86

50. Beatty WW. RBANS analysis of verbal memory in multiple sclerosis. Arch Clin Neuropsychol 2004;19:825-34.

\section{Accepted on 25-09-2006}

Source of Support: Nil, Conflict of Interest: None declared. 